\title{
Cross-sectional relationship of perceived familial protective factors with depressive symptoms in vulnerable youth
}

\author{
Hanna E. Schwendemann ${ }^{1 *}$, Heidi Kuttler², Thomas Mößle ${ }^{3}$ and Eva Maria Bitzer ${ }^{1}$
}

\begin{abstract}
Background: There are multiple negative consequences associated with heavy episodic drinking and close associations between substance abuse and depression, alcohol-intoxicated adolescents (AIA) represent a vulnerable group. We aim to add to the current literature by investigating the cross-sectional relationship of perceived familial protective factors with depressive symptoms in AIA in hospitals, with respect to sex. Depression is among the 10 leading causes of disabilities during childhood and adolescence, with girls being more vulnerable than boys. Considerable evidence reveals a strong association between depression and alcohol abuse. The family provides the possibility to positively influence depressive symptoms.

Methods: We present cross-sectional data of a German multisite, epidemiological cohort study on AIA. By using youth's self-reports, we assessed sociodemographic data, as well as data on perceived familial protective factors and depressive symptoms using items of the Communities that Care Youth Survey instrument. We performed descriptive and multigroup analyses to evaluate the measurement invariance of the used instruments. Moreover, to investigate the relationships between the constructs, we used structural equation modelling.

Results: The study sample comprised 342 AIA, with a mean age of 15.5 years ( $S D=1.2 ; 48.1 \%$ girls). The final structural equation model achieved an acceptable model fit of $X^{2}(69,342)=110.056 ; p=.001 ; T L I=0.97 ; C F I=0.98 ; R M S E A=0.046$; $\mathrm{SRMR}=0.042$, and the rewards for prosocial involvement in the family context correlated significantly negatively with present depressive symptoms, $(B=-0.540, p<0.001)$. The effects were stronger in boys $(B=-0.576, p<0.001)$ than in girls $(B=-0.519, p<0.001)$.

Conclusion: In vulnerable youth in Germany, depressive symptoms are correlated to good experiences within the family. Future research should assess whether interventions that enhance parental support reduce the risk of depressive symptoms in AIA. Our findings highlight the need for family-based prevention programmes, particularly for AIA with an increased risk of depression.
\end{abstract}

Keywords: depressive symptoms, adolescents, familial protective factors, resilience, family structure

\section{Background}

Approximately $15-20 \%$ of all children and adolescents experience depressive symptoms during childhood and adolescence, and depression is among the 10 leading causes of disability in this age group [1-4]. In Germany, almost $18 \%$ of children and adolescents experience such symptoms at least once in their lifetime, and in $4 \%$ of

\footnotetext{
* Correspondence: hanna.schwendemann@ph-freiburg.de

${ }^{1}$ Pädagogische Hochschule Freiburg/University of Education, Kunzenweg 21,

79117 Freiburg, Germany

Full list of author information is available at the end of the article
}

German adolescents, depression persists for a minimum of 2 years $[2,5]$. Depressive symptoms in youth are a predictor of depression in adulthood $[3,5]$. The female sex is an established factor for depression, with the risk in puberty for girls being twice as high as that for boys $[6,7]$.

Alcohol is one of the most significant risk factors for morbidity and mortality in young people worldwide, and alcohol misuse and episodic heavy drinking is a significant public health concern $[8,9]$. More than one-third of 15-16-year olds in Europe have reported excessive alcohol consumption in the last 30 days, and $13 \%$ have 
been intoxicated in the last 30 days [10]. Regular, augmented, or excessive alcohol consumption is often associated with alcohol abuse in later life, as well as with depression during adolescence. Both frequency and extent of alcohol consumption have emerged as significant predictors of higher levels of depression [11-17], and heavy episodic drinking in adolescence can furthermore be an indicator of already existing disorders. Hospitalised intoxicated adolescents are a vulnerable group whose healthy development is endangered. At the same time, the hospitalization of adolescents because of excessive alcohol consumption presents an opportunity to initiate preventive efforts [18].

Models of risk and protective factors have predicted the onset and progression of disorders [19-22]. The Social Development Model (SDM) provides a framework for explaining healthy or problematic development, in which family environment and social interactions emerge as relevant factors influencing youth's development $[19,23,24]$. It is evident that (1) opportunities for prosocial involvement and interaction with others, (2) the degree of involvement and interaction, (3) the skills to participate, and (4) receiving rewards for prosocial involvement lead to bonding processes within the social environment and act as protective factors [23, 25-27]. Less attachment to parents as well as family conflicts are risk factors for depression [6]. Currently, few studies have investigated the relationship between resilience, protective factors, and problem behaviour or mental disorders in young people $[5,28]$.

The family, as an instant, lasting, and influential environment for children and youth, protects against the development of psychopathology and provides opportunities for preventive interactions [29-31]. Parents are the central caretakers of children and youth, may influence their attitudes and behaviours, and contribute to their socialisation [32,33]. Adolescents' family relationship, family climate, and cohesion can be a risk or a protective factor against depression [5, 34, 35]. Better parent-adolescent communication, parental connectedness, shared activities, and warmth are associated with fewer mental disorders and are strongly protect against depressive symptoms [7, 36].

In this study, we present cross-sectional results of a German multisite, epidemiological cohort study on adolescents hospitalised due to alcohol intoxication (International Classification of Diseases, Tenth Revision (ICD 10) F10.0). Because of the multiple negative consequences associated with heavy episodic drinking and close associations between substance abuse and depression, alcohol-intoxicated adolescents (AIA) represent a vulnerable group. The influence of protective factors in the context of depressive symptoms in AIA has not been well studied. We aim to add to the current literature by investigating the cross-sectional relationship of family protective factors with depressive symptoms in AIA, using the SDM.

In the current study, we examined whether according to the SDM, opportunities for prosocial involvement in the family context lead to rewards for prosocial involvement and cause a good attachment to the mother and father. Furthermore, we investigated whether in compliance with the SDM, good bonding to one's parents reduces depressive symptoms in AIA. Because depressive symptoms vary with sex, we analysed whether group differences existed in AIA.

\section{Methods}

\section{Study design}

We collected cross-sectional data in a German multisite, epidemiological cohort study, conducted between June 2012 and October 2013. The survey was conducted in co-operation with 10 prevention centres throughout Germany applying the national prevention programme HaLT/"Close to the limit" [9]. This programme targets youth aged 11-17 years hospitalised with acute alcohol intoxication (ICD-10 F10.0) diagnosed by the referring physician in the emergency room. It aims to prevent the stabilisation of heavy alcohol consumption among children and adolescents [9]. HaLT involves two components: a proactive strategy/structural prevention component in the community setting and a reactive strategy, where social workers execute a brief intervention. This intervention is based on motivational interviewing, at patients' bedside, typically the day after the intoxication incident $[9,37,38]$. To conduct the current survey, the trained social workers recruited the survey participants before the brief intervention and interviewed AIA aged 13-18 years, during their hospital stay.

We defined inclusion criteria (participants should be aged 13-18 years and hospitalised due to alcohol intoxication) and exclusion criteria (not in the desired age group and another reason for hospitalisation). Informed consent of both parents and adolescents was collected by the social workers, who subsequently handed over a written questionnaire to the adolescents. Prevention centres documented all cases of acute alcohol intoxication during the study period and number of study participants. The study participation was $69 \%$. Non-participation was based on either refusal to participate in the survey $(15.5 \%)$, acute need of support (10.9\%), or low literacy (4.6\%) [39]. The participating adolescents received a USB flash drive and a 10-Euro voucher as an incentive.

\section{Measures}

Perceived familial protective factors and depressive symptoms were assessed based on self-reports of the 
youth as well as sociodemographic data (sex, age, and family structure).

\section{Familial protective factors}

Perceived familial protective factors were recorded using the German version [40] of the Communities That Care (CTC) Youth Survey instrument [19]. The CTC instrument is designed to assess a broad set of risk and protective factors across different domains: community, school, family, peers, and individuals, as well as health and behavioural outcomes [19].

The CTC instrument evolved from the SDM and has been used in the USA and other countries. In Germany, there is an adapted German version of the CTC instrument, which we used in our study [41, 42]. For our analysis, four scales of the CTC-protective family domain with 11 items are included. This selection is based on our previous study on the psychometric properties of the CTC instrument [18]. The attachment of adolescents to their mother and father is measured by three items each. For example, "Do you feel close to your mother?" and "Do you feel close to your father?" Opportunities for prosocial involvement in the family context are measured by three items (e.g., "My parents notice when I am doing a good job and let me know about it") and rewards for prosocial involvement by two items (e.g., "My parents ask me what I think before most family decisions affecting me are made"). The response categories for the attachment to the mother and father are measured using the following scores: $1=$ 'no', 2 = 'rather no', $3=$ 'rather yes', and $4=$ 'yes'. Response categories for opportunities and rewards for prosocial involvement ranged from $1=$ 'very wrong' to $4=$ 'very right'. When summing each scale, high scores represent high familial protection. The Cronbach's $\alpha$ of the scales are sufficient, attachment to mother: $\alpha=0.80$, attachment to father: $\alpha$ $=0.88$, opportunities for prosocial involvement: $\alpha=0.74$, and rewards for prosocial involvement: $\alpha=0.87$ [18].

We followed the recommendation of Arthur et al. (2007) to calculate cut-off values for the scales (whether protective factor is present) [43]. This implies three steps: 1 ) identifying the scale mean, 2) calculating the mean absolute deviation (MAD) according to Leys (2013) [44], 3) deducting the scale mean with $15^{*} \mathrm{MAD}$ (cut-off points: attachment to mother $=2.85$, attachment to father $=2.85$, opportunities for prosocial involvement $=3.26$, and rewards for prosocial involvement $=3.39$ ) [45].

\section{Depressive symptoms}

We assessed depressive symptoms with the following items of the CTC instrument [19]: "Sometimes I think life is not worth it," "All in all, I am inclined to think I am a failure," and "In the past year, have you felt depressed or sad MOST days, even if you felt okay sometimes?" The response options ranged as follows: 1 = 'no', $2=$ 'rather no', $3=$ 'rather yes', and $4=$ 'yes'. Cronbach's $\alpha$ in our AIA sample was 0.80 .

To analyse present depressive symptoms, we summed the answers of all three items of the scale. We assumed depressive symptoms, if at least one answer to one of the three items was 'yes' or 'rather yes', and the sum of the added values has more than 6 points. A recent study on American students (age $\mathrm{M}=19.2, \mathrm{SD}=0.44$ years) showed a high accuracy of the four-item depression scale of the CTC instrument compared with the Patient Health Questionnaire with 9 items (PHQ-9). The four items reflect the Diagnostic and Statistical Manual of Mental Disorders-5 criteria very well, and three of the four items measure cognitive symptoms, which are strongly discriminant of other depressive symptoms [46].

\section{Statistical analysis}

We calculated frequencies and tested patterns of the missing values. The overall frequency of missing values was low $(77.8 \%$ of respondents with less than $5 \%$ missing data). The missing values were either completely missing at random or missing at random.

Descriptive statistics (mean and proportions) were calculated, and the data were checked for normality. We analysed the construct validity of the familial protective scales and depressive symptoms through confirmatory factor analysis (CFA). As advised by Cole (2007), we allowed correlations between residual terms of the attachment to the mother and father scales, that are implied by the measurement strategy, which are the equally expressed items of the mother and father [47].

We performed structural equation modelling (SEM) to investigate the relationship between the family protective factors and depressive symptoms in AIA using the SDM.

First, we tested the measurement invariance of the SEM multigroup modelling with respect to sex. Configural invariance is present if the factor structure, loading pattern, and intercepts are similar in both groups [48]. For testing weak invariance, the factor loadings are set equal across groups. If this models proves the stage, structural relationship between groups, such as factor correlations, can be examined and compared across groups [49]. Strong invariance is tested by additionally constraining the intercepts to be equal across groups. Confirmation allows a comparison of latent means and regression parameters between groups [50-52]. The nested model is compared with the previous less restricted model by a $X^{2}$ difference test. As noted by Chen (2007), $\chi^{2}$ differences have the same problem as absolute $\chi^{2}$ tests by being highly sensitive to the sample size and violations of the normality assumption. Therefore, goodness-of-fit statistics are recommended. When 
the sample size is adequate $(n>300)$, a change of the $\Delta$ comparative fit index $(\mathrm{CFI}) \leq-0.010$ supplemented by a change in the $\Delta$ root mean square error of approximation (RMSEA) $\leq 0.015$ indicates invariance [53]. An analysis of partial measurement invariance is possible, if the nested model is worse than the previous model. Partial invariance is present if at any of the restrictions of the aforementioned stages are freed for some indicators to improve the model fit [48]. If at one stage, partial invariance is present, then this partial model is the basis for the next step of assessing measurement invariance [48].

To analyse the differences in path coefficients with respect to sex, we performed model comparisons by using the $x^{2}$ differences of the restricted model (equal constraint regressions) and the model without the restriction. For model comparisons, we used the Satorra-Bentler-scaled $\chi^{2}$ difference test using difference test scaling correction and the differences in the degree of freedom [54].

We applied the maximum likelihood estimator with robust standard errors (MLR) to obtain appropriate fit indices [55]. We used the CFI, Tucker-Lewis Index (TLI), and RMSEA to evaluate the model fit. Furthermore, we checked the standardised root mean square residual (SRMR <0.1). The following parameter estimates and goodness-of-fit statistics describe an acceptable model fit; CFI and TLI $\geq 0.90$, RMSEA $\leq 0.08$. Moreover, a good model fit is represented by the following estimates; CFI and TLI $\geq 0.97$ and RMSEA $\leq 0.05$, which were used to evaluate the model data [56].

For the descriptive and multivariate analyses, we used SPSS Version 22 (IBM Corp. Released 2013. IBM SPSS Statistics for Windows, Version 22.0. Armonk, NY: IBM Corp). For the CFA, SEM, and measurement invariance tests, we used R (Version 3.2.4) with the missForest, semTools and lavaan packages $(0.5-20)[55,57,58]$.

\section{Results}

\section{Subject characteristics}

The study cohort consisted of 342 AIA in hospital, with a mean age of 15.5 years ( $\mathrm{SD}=1.2,48.1 \%$ girls). Among all adolescents, $46.8 \%$ lived in a traditional family. Among the remaining $53.2 \%$ of adolescents, most lived with a single mother (Table 1).

\section{Confirmatory factor analysis}

First, we investigated the latent structure of the perceived familial protective factors and depressive symptoms. The four familial protective scales $\left(\chi^{2}(35\right.$; $342)=56.380, \quad p=0.012 ; \quad$ TLI $=0.979 ; \quad$ CFI $=0.985$; RMSEA $=0.047$, SRMR $=0.029$ ) and depressive symptoms represented independent factors. All estimated measurement loadings were significant, and the goodness-of-fit statistics was acceptable (Figs. 1 and 2).
Table 1 Sociodemographic variables of the study population $(n=342)$

\begin{tabular}{lll}
\hline & N valid & $n(\%)$ \\
\hline Female sex & 337 & $162(48.1)$ \\
Traditional family $^{a}$ & 340 & $159(46.8)$ \\
Familial protective factors & & \\
$\quad$ Attachment to mother (good) & 321 & $198(61.7)$ \\
Attachment to father (good) & 316 & $159(50.3)$ \\
Opportunities for prosocial involvement (good) & 324 & $173(53.4)$ \\
Rewards for prosocial involvement (good) & 323 & $166(51.4)$ \\
Depressive Symptoms & 337 & $104(30.9)$ \\
Sometimes I think life is not worth it & 332 & $97(29.2)$ \\
All in all, I am inclined to think I am a failure & 331 & $72(21.2)$ \\
In the past year have you felt depressed or sad & 331 & $88(26.6)$ \\
MOST days, even if you felt okay sometimes? & & \\
Age & 310 & M $=15.5$ \\
& & $(S D=1.2)$ \\
$\leq 13$ & & $18(5.8)$ \\
$14-15$ & & $120(35.1)$ \\
$16-17$ & & $3(0.9)$ \\
\hline 18
\end{tabular}

$M$ mean, $S D$ standard deviation

${ }^{a}$ traditional family - living with both parents

Relationship between perceived familial protective factors and depressive symptoms

We analysed the relationship of perceived familial protective factors with depressive symptoms using the SDM $\left(\chi^{2}(69,342)=162.847 ; p<0.001\right.$; TLI $=0.94 ;$ CFI $=0.95$; RMSEA $=0.070$; SRMR $=0.065)$. In the SDM, opportunities for prosocial involvement in the family led to rewards for this involvement. Positive engagement in the family context resulted in a good attachment to the mother and father. We assume, that there is a possibility that the SDM is conceivable in either direction; Therefore, we analysed the SEM vice versa. This led to the model that fitted best to the data. The SDM-reverse model achieved a better model fit of $\chi^{2}(69,342)=$ $110.056 ; \quad p=0.001 ; \quad \mathrm{TLI}=0.97 ; \quad \mathrm{CFI}=0.98 ; \quad$ RMSEA $=$ 0.046; SRMR = 0.042; Fig. 3).

Because of the cross-sectional data, we analysed the influence of depressive symptoms on perceived rewards for prosocial involvement as well, which resulted in a comparable model adjustment $\left(\chi^{2}(67,342)=107.947 ; p=0.001\right.$; $\mathrm{TLI}=0.97 ; \mathrm{CFI}=0.98 ; \mathrm{RMSEA}=0.047 ; \mathrm{SRMR}=0.038$ ).

Our cross-sectional analysis revealed that a good attachment to the mother $(B=0.815, p<0.001)$ and father $(B=$ $0.447, p<0.001$ ) led to opportunities for prosocial involvement in the family context. Opportunities for prosocial involvement were significantly positively associated with rewards for prosocial involvement in the family context $(\beta=0.844, p<0.001)$. The SEM showed that rewards 


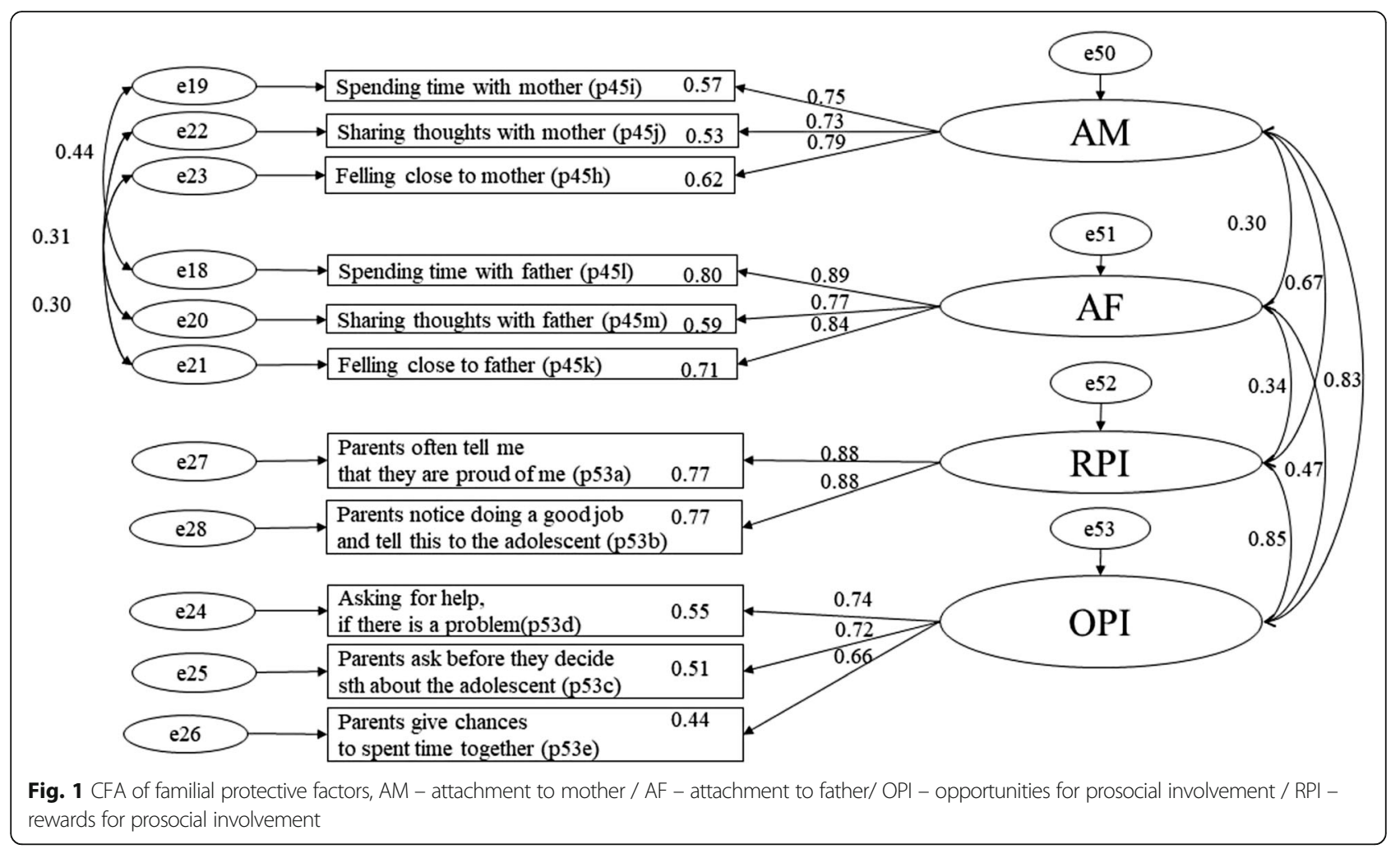

for prosocial involvement were significantly negatively related to depressive symptoms. The higher the perceived familial rewards for prosocial involvement were pronounced, the lower was the symptom appearance of depression $(ß=-0.540 ; p<0.001)$. Vice versa, we observed that adolescents with higher levels of depressive symptoms perceived lower rewards for prosocial involvement in the family context $(ß=-0.538, p<0.001)$.

\section{Measurement invariance}

Table 2 shows the results of the hierarchical measurement invariance with respect to sex. The fit statistics of the analysis showed that configural and weak invariance can be assumed. With respect to strong invariance, the changes in the CFI and RMSEA compared with the weak model were larger than -0.010 and 0.015 , respectively. In order to test partial weak invariance, the modification indices for individual parameters were examined. By freeing the loadings of the items p45h ("Feeling close to mother") and r28a ("Sometimes I think life is not worth it"), the $\triangle$ CFI and $\triangle$ RMSEA were below their cut-off points, indicating a partial strong invariance.

\section{Familial protective factors and depressive symptoms with respect to sex}

We analysed the final SEM model for differences between boys and girls, using multigroup analysis. We tested the nested model, where we constrained the path

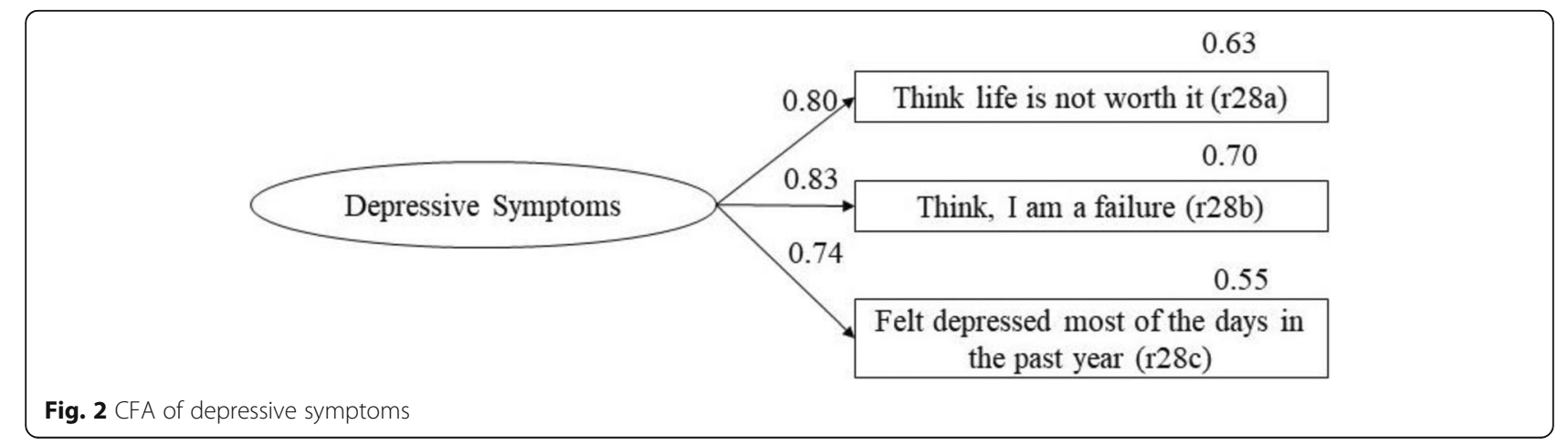




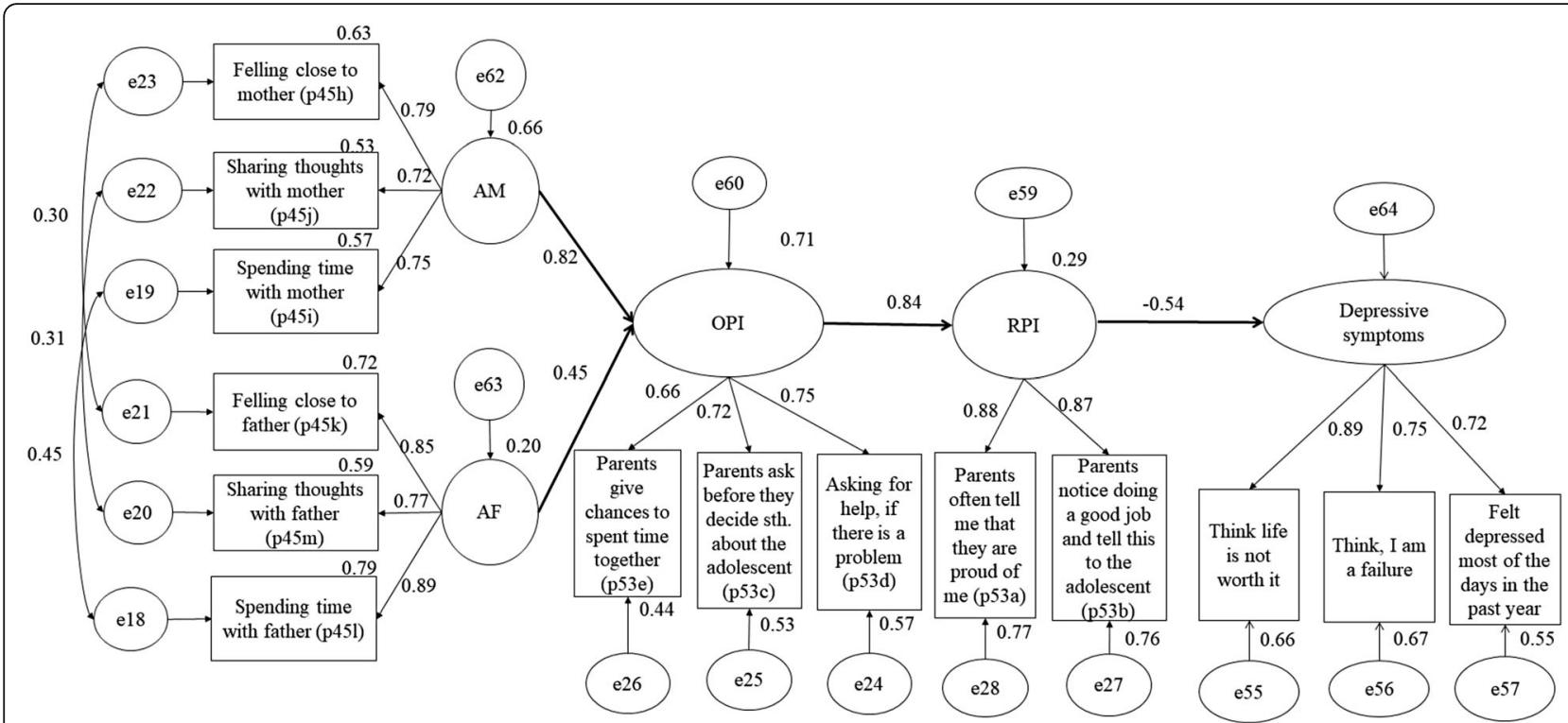

Fig. 3 SEM of familial protective factors and depressive symptoms in AIA $(n=342)$ : AM - attachment to mother / AF - attachment to father / $\mathrm{OPI}$ - opportunities for prosocial involvement / RPI - rewards for prosocial involvement

coefficients of the SEM against the unconstrained model. Sex showed a moderating effect on the SEM $\Delta \chi^{2}=$ $11.335(\Delta \mathrm{df}=4, p=0.023)$. Compared with girls, boys perceive their mothers and fathers to provide less opportunities for prosocial family involvement (mothers: boys, $\beta=0.727, p<0.001$ and girls, $\beta=0.857, p<0.001$; fathers: boys, $\beta=0.399, p<0.001$ and girls: $\beta=0.462, p<0.001$ ). For engagement in the family, boys perceive more rewards $(B=0.867, p<0.001)$ than do girls $(B=0.843, p<$ $0.001)$. These rewards significantly reduce depressive symptoms in both boys $(B=-0.576, p<0.001)$ and girls $(B=-0.519, p<0.001)$. A comparison of the latent means between girls and boys in the multigroup analysis revealed that boys were less affected by depressive symptoms $(\Delta \mathrm{M}=-0.438$; Wald- $\mathrm{z}=-4.588 ; p<0.001)$ and less attached to their mothers $(\Delta \mathrm{M}=-0.276$; Wald $-\mathrm{z}=-$ $3.621 ; p<0.001$ ) than were girls (Fig. 4).

\section{Discussion}

In this study, we analysed cross-sectional data of the vulnerable target population of AIA with respect to perceived familial protective factors and their relationship to depressive symptoms during hospital stay.

One-third of AIA experience depressive symptoms. The prevalence of depressive symptoms in AIA is comparable with that in representative samples [39]. Furthermore, more than $50 \%$ of AIA grow in non-traditional families, which accounts for an important risk factor for mental disorders, such as depression [5, 34]. A comparison of perceived familial resources of AIA with those of a representative sample of adolescents clearly showed that AIA have fewer opportunities and rewards for prosocial involvement, but the attachment to parents was almost the same in AIA and representative samples [59, 60].

We proved that the CTC scales used to measure perceived familial protective factors and depressive symptoms represent independent latent factors using CFA. The SEM was partial strong invariant in boys and girls, which is an important prerequisite for meaningful group comparisons.

Our data fit best to a SEM resembling a sort of 'reversed SDM'. According to the SDM, opportunities

Table 2 Results of the measurement invariance analysis of the SEM comparing boys and girls (MLR estimator)

\begin{tabular}{llllllllc}
\hline $\begin{array}{l}\text { Model } \\
\text { Thresholds }\end{array}$ & $x^{2}$ & $d f$ & $\Delta x^{2}$ & $p$ & CFI & $\begin{array}{l}\Delta \text { CFI } \\
\leq-0.010\end{array}$ & $\begin{array}{l}\text { RMSEA } \\
\leq 0.015\end{array}$ \\
\hline Configural invariance & 245.462 & 134 & & $<0.001$ & 0.950 & & 0.074 \\
Weak invariance & 254.394 & 143 & 8.932 & $<0.001$ & 0.950 & -0.000 & 0.072 & 0.002 \\
Strong invariance & 284.859 & 152 & 30.465 & $<0.001$ & 0.941 & -0.009 & 0.076 & -0.002 \\
Partial strong invariance $^{a}$ & 266.094 & 151 & 11.700 & $<0.001$ & 0.949 & -0.001 & 0.071 & 0.001 \\
\hline
\end{tabular}

${ }^{\mathrm{a}}$ Freeing of the intercepts of the items p45h and $\mathrm{r} 28 \mathrm{a}$ 


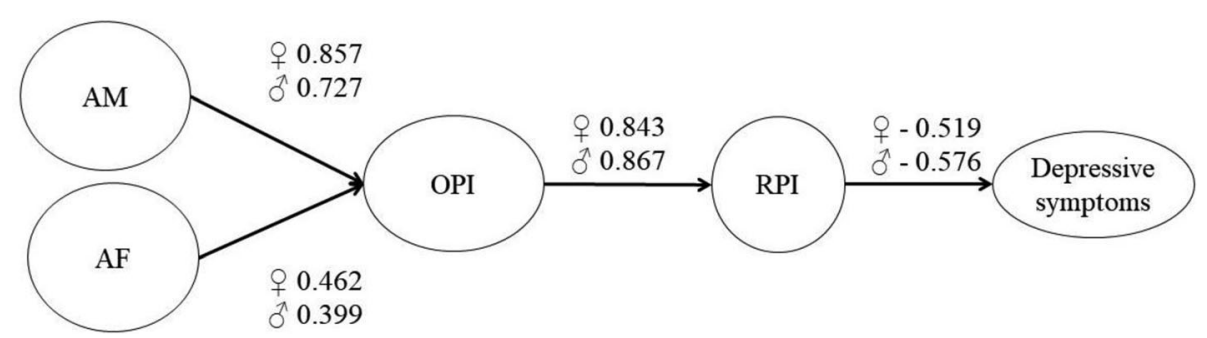

Fig. 4 SEM of familial protective factors and depressive symptoms in AIA - differences across sex ( $n=342)$ : AM - attachment to mother /AF attachment to father / OPI - opportunities for prosocial involvement / RPI - rewards for prosocial involvement

and rewards for prosocial engagement are important for fostering familial prosocial socialisation that results in attachment to both parents $[26,61]$. Our final model indicates that a good attachment to the mother and father offers opportunities for prosocial involvement in the family context, which results in rewards for prosocial involvement and reduces depressive symptoms. In adolescence, a good relationship to both parents is central for gaining autonomy. Parents with a secure attachment are more responsive and more supportive toward their children to gain autonomy and enable decision-making in adolescents. The search for physical closeness in childhood is replaced with communication about thoughts and feelings of the adolescents [62-64]. The phenomenon of a reverse-SDM path in vulnerable youth should be investigated in a representative sample of adolescents.

As indicated in the literature, adolescents' family relationship, family climate, and cohesion protect against depression [5, 34, 35]. We showed that in AIA, perceived parental rewards for prosocial involvement as developmental resources are negatively correlated with depressive symptoms. This result helps social workers to support AIA and their family in the situation of hospitalisation as an important starting point for addressing preventive interventions.

Multigroup analysis revealed that these results are valid for both boys and girls. However, significant differences existed between boys and girls. Girls perceive having more opportunities to engage in the family context obtained from their mothers, but boys perceive getting more rewards for prosocial involvement. These rewards result in a significantly stronger reduction of depressive symptoms in boys. With respect to mean differences in depressive symptoms in AIA, we observed that girls had more depressive symptoms than did boys. Studies have reported considerable sex differences not only in the number of depressive symptoms but also in the structure of protective factors. For instance, spending time with the family is particularly protective for boys buffering depressive symptoms $[65,66]$.
The fact that $53.2 \%$ of AIA live with only one parent as well as the negative influence of familial protective factors on depressive symptoms highlights the importance of integrating mothers and fathers within the context of AIA. Furthermore, when working with AIA having depressive symptoms, focus should be placed on familial protective factors. Parental support and emotional warmth confer protective against depressive symptoms [35, 67]. Increasing familial protective factors predicts a decrease in depressive disorders [5]. The incidence rate of depression is considerably higher in adolescents with low parental support than in their high parental support counterparts [1]. AIA have less familial protective factors than representative samples, are more likely to live with a single parent, and have a higher risk of depressive symptoms. Therefore, in AIA, it is necessary to thoroughly evaluate depressive symptoms, family structure, familial protective factors, and sex to prevent a problematic development. One possibility for developing familial protective resources is the 'Strengthening Families Programme', which addresses parents and their vulnerable youth to improve familial communication and interaction, clarifying rules and emphasising caring and warm relationship $[68,69]$.

The protective function of family factors is particularly important for single parents because the risk factors for mental disorders and substance abuse in adolescence accumulate when there are, for example, family conflicts, financial problems, and lack of joint activities [70]. This risk is especially present in boys [71]. Addressing family protective factors and integrating the second parent, which is the father in most cases, can be an important resource in the family environment of adolescents. Familial protective factors are correlated with depressive symptoms in AIA; therefore, the opportunity to address these factors in the context of hospitalisation should be used.

\section{Strengths and limitations}

One of the strengths of this study is the multicentre design integrating vulnerable youth during their hospital stay. It is difficult to reach AIA in routine care, but our 
study consulted in collaboration with social workers examined more than 300 AIA at 10 hospitals in Germany. We assessed depressive symptoms in hospitalised AIA and perceived familial protective factors; our results add to the scarce literature on this vulnerable target group. We assessed familial protective factors via self-reports because of the survey setting; the feasibility of this empirical inquiry has been indicated in the literature $[5,34,36,72]$. To confirm the assessment of depression, we crosschecked AIA self-reported depression with the estimated need to initiate social support (i.e., contacting the youth welfare office, drug and family counselling) collected from trained social workers. AIA reporting depressive symptoms received more offers of social support than did the youth not reporting depressive symptoms $[39,45]$.

Our results are limited by the fact that we only assessed depressive symptoms with three items of the CTC instrument and not via a standardised instrument, such as the PHQ-9, the Beck Depression Inventory, or a diagnostic interview [46]. In this study, we used the CTC instrument to obtain an impression of depressive symptoms in AIA. Briefly, we did not want to diagnose depression, but rather to identify the need for action in adolescents and provide this information to health care professionals outside the hospital setting. It must be considered that we asked the youth for depressive symptoms in the year before hospitalisation. In our analyses, we could only evaluate the relationship of perceived familial protective factors with reported depressive symptoms at the hospital because of the cross-sectional nature of the data. Data on the midterm development (a 6-month follow-up) of depressive symptoms are available, but were not included in the present study because its small sample size did not allow for a valid analysis. Furthermore, this decision was taken due to differing time spans in the assessment of depressive symptoms. At the hospital, items were used with the original wording, and at T1, the time span was changed for the 6 months since hospitalisation [39].

In addition to familial influences on depressive symptoms, peers play an important role in the lives of adolescents. Their influence can limit the influence of parents [7, 73]. This idea may be integrated in further research on factors protecting against depressive symptoms in AIA, but was not included in the present analysis.

Future research should evaluate the medium-term effects of protective factors on the development of depressive symptoms in AIA. The emergency setting could be used for assessing the risk profiles of AIA that focus on developmental hazards, as well as individual and familial protective factors to identify at-risk groups and offer opportunities for interventions. An intervention study would provide a good opportunity to investigate the medium-term effects of interventions in enhancing familial protective factors in AIA.

\section{Conclusion}

The present findings reveal relationships among depressive symptoms in girls and boys and good experiences within the family, a good attachment to the mother and father, opportunities for prosocial involvement, and rewards for this positive involvement in the family context. The cross-sectional buffering effect of rewards for prosocial involvement is particularly strong in boys. Identifying depressive symptoms in hospitals can be an important starting point for preventive programmes and early interventions to reduce the existing symptoms by reinforcing familial resources; additionally, familial protective factors are helpful for addressing the needs of adolescents at a risk of major depression.

Future research should investigate whether interventions that enhance parental support reduce the risk of depressive symptoms in adolescents after alcohol intoxication. Strengthening familial protective factors may influence the onset of symptoms, and existing symptoms may also be affected by familial resources, such as family climate and social support [5]. Our findings highlight the need for family-based prevention programmes, particularly for AIA having an increased risk of depression.

\section{Abbreviations \\ AIA: Alcohol intoxicated adolescents; CFA: Confirmatory factor analysis; CFI: Comparative fit index; CTC: Communities that care youth survey instrument; MAD: Mean absolute deviation; MLR: Maximum likelihood estimator with robust standard errors; PHQ-9: Patient health questionnaire with 9 items; RMSEA: Root mean square error of approximation; SDM: Social development model; SEM: Structural equation model; SRMR: Standardised root mean square residual; TLI: Tucker-Lewis Index}

\section{Acknowledgements}

The authors thank all adolescents and parents for their participation, as well as the hospital staff for their vast support. Thanks to all the social workers in the HaLT-prevention-centres in Bad Homburg, Berlin, Bielefeld, Kassel, Leipzig, Lörrach, Rastatt/Baden-Baden, Schweinfurt, Wiesbaden, and Worms. The authors thank Mr. F. Groeger-Roth from the Federal Prevention Council of Lower Saxony (Landespräventionsrat Niedersachsen) and Prof. Dr. R. Soellner, Universität Hildesheim. We also thank the RiScA-Group (Risk and Protective

Factors in the Context of Acute Alcohol Intoxication in Childhood and Adolescence group), which includes (in addition to the authors Hanna Schwendemann, Heidi Kuttler and Eva Maria Bitzer) Stefanie Bumke, Cornelius Groß, Ludwig Kraus, Daniela Pionthek, Olaf Reis, and Ullrich Zimmermann

\section{Authors' contribution}

HS planned and performed the data analysis and drafted the manuscript. HK conceived the study and participated in its design, coordination, and data acquisition. TM played an advisory role in performing the data analysis and interpreting its results. EMB provided substantial input to the study design, statistical analysis, and data interpretation. HK, TM, and EMB revised the manuscript critically for important intellectual content.

\section{Funding}

The study was funded by the German Ministry of Health (grant ID: IA5 2511DSM220), which played no role in the study design, data collection, analysis, and interpretation or manuscript drafting.

Availability of data and materials

The datasets generated and analysed during the current study are not publicly available due to data protection. 


\section{Ethics approval and consent to participate}

The Ethics Commission of the State Medical Association Baden-Wuerttemberg approved the study (Germany, May 22, 2012; No. F-2012-035). We obtained written permission to participate in the study from parents and adolescents.

\section{Consent for publication}

Not applicable

\section{Competing interests}

On behalf of all authors, the corresponding author declares having no competing interests.

\section{Publisher's Note}

Springer Nature remains neutral with regard to jurisdictional claims in published maps and institutional affiliations.

\section{Author details}

'Pädagogische Hochschule Freiburg/University of Education, Kunzenweg 21, 79117 Freiburg, Germany. ${ }^{2}$ Cooptima, Talweg 44, 79540 Lörrach, Germany. ${ }^{3}$ State Police College Baden-Württemberg, Sturmbühlstraße 250, 78054 Villingen-Schwenningen, Germany.

\section{Received: 13 February 2017 Accepted: 25 January 2018} Published online: 07 February 2018

\section{References}

1. Seeley J, Stice E, Rohde P. Screening for depression prevention: identifying adolescent girls at high risk for future depression. J Abnorm Psychol. 2009; 118:161-70. https://doi.org/10.1037/a0014741.

2. Barkmann C, Schulte-Markwort M. Prevalence of emotional and behavioural disorders in German children and adolescents: a meta-analysis. J Epidemiol Community Health. 2012;66:194-203. https:/doi.org/10.1136/jech.2009.102467.

3. Costello EJ, Foley Debra L, Angold A. 10-year research update review: the epidemiology of child and adolescents psychiatric disordern: II. Developmental epidemiology. J AM ACAD Child Adolesc Psychiat. 2006:45: 8-24. https://doi.org/10.1097/01.chi.0000184929.41423.c0.

4. Mokdad AH, Forouzanfar MH, Daoud F, Mokdad AA, El Bcheraoui C, MoradiLakeh $\mathrm{M}$, et al. Global burden of diseases, injuries, and risk factors for young people's health during 1990-2013: a systematic analysis for the global burden of disease study 2013. Lancet. 2016;387:2383-401. https://doi.org/10 1016/S0140-6736(16)00648-6

5. Klasen F, Otto C, Kriston L, Patalay P, Schlack R, Ravens-Sieberer U. Risk and protective factors for the development of depressive symptoms in children and adolescents: results of the longitudinal BELLA study. Eur Child Adolesc Psychiat. 2014; https://doi.org/10.1007/s00787-014-0637-5.

6. Belhadj Kouider E, Petermann F. Common risk factors of depressive and anxiety Symptomatics in childhood and adolescence: a systematic review from Transdiagnostic perspectives. Fortschr Neurol Psychiatr. 2015;83:32133. https://doi.org/10.1055/s-0035-1553089.

7. Patton GC, Sawyer SM, Santelli JS, Ross DA, Afifi R, Allen NB, et al. Our future: a lancet commission on adolescent health and wellbeing. Lancet. 2016;387:2423-78. https://doi.org/10.1016/50140-6736(16)00579-1.

8. Catalano RF, Fagan AA, Gavin LE, Greenberg MT, Irwin CE, Ross DA, Shek DTL. Worldwide application of prevention science in adolescent health. Lancet. 2012:379:1653-64.

9. Diestelkamp S, Arnaud N, Sack P-M, Wartberg L, Daubmann A, Thomasius R. Brief motivational intervention for adolescents treated in emergency departments for acute alcohol intoxication - a randomized-controlled trial. BMC Emerg Med. 2014:14:13, https://doi.org/10.1186/1471-227X-14-13.

10. ESPAD Group. ESPAD report 2015: results from the European school survey project on alcohol and other drugs. Luxembourg; 2016.

11. Cairns KE, Yap, Hui MB, Pilkington PD, Jorm AF. Risk and protective factors for depression that adolescents can modify: a systematic review and metaanalysis of longitudinal studies. J Affect Dis. 2014;169:61-75. https://doi.org/ 10.1016/j.jad.2014.08.006.

12. Bitzer EM, Grobe TG, Schilling E, Dörning H, Schwartz F. Schwerpunktthema: Alkoholmissbrauch bei Jugendlichen. Focus topic: Alcohol abuse in adolescents. Asgard-Verl: St. Augustin; 2009.

13. Behrendt S. Buchbesprechungen. Book reviews. Sucht. 2008;54:354-61.

14. Buchmann AF, Schmid B, Blomeyer D, Zimmermann US, Jennen-Steinmetz C, Schmidt MH, et al. Drinking against unpleasant emotions: possible outcome of early onset of alcohol use? Alcohol Clin Exp Res. 2010;34:1052-7. https://doi. org/10.1111/j.1530-0277.2010.01180.x.

15. Buchmann AF, Schmid B, Blomeyer D, Becker K, Treutlein J, Zimmermann US, et al. Impact of age at first drink on vulnerability to alcohol-related problems: testing the marker hypothesis in a prospective study of young adults. J Psychiat Res. 2009;43:1205-12. https://doi.org/10.1016/j.jpsychires. 2009.02.006.

16. Skogen JC, Sivertsen B, Lundervold AJ, Stormark KM, Jakobsen R, Hysing M. Alcohol and drug use among adolescents: and the co-occurrence of mental health problems. Ung@hordaland, a population-based study. BMJ Open. 2014;4:e005357. https://doi.org/10.1136/bmjopen-2014-005357.

17. Edwards AC, Heron J, Dick DM, Hickman M, Lewis G, Macleod J, Kendler KS. Adolescent alcohol us is positively associated with later depression in a population-based U.K. cohort. J Stud Alcohol Drugs. 2014;75:758-65.

18. Kuttler $\mathrm{H}$, Schwendemann $\mathrm{H}$, Bitzer EM. Familial risk and protective factors in alcohol intoxicated adolescents: psychometric evaluation of the family domain of the communities that care youth survey (CTC) and a new short version of the childhood trauma questionnaire (CTQ). BMC Pediatr. 2015;15: 1-14. https://doi.org/10.1186/s12887-015-0471-z.

19. Arthur MW, Hawkins JD, Pollard JA, Catalano RF, Baglioni AJ Jr. Measuring risk and protective factors for substance use, delinquency, and other adolescent problem behaviors: the communities that care youth survey Eval Rev. 2002;26:575-601. https://doi.org/10.1177/019384102237850.

20. Bond L, Lyndal T, Tombourou JW, Patton GC, Catalano RF. Improving the lives of young victorians in our community: a survey or risk and protective factors. Centre for Adolescent Health: Melbourne; 2000.

21. Sawyer SM, Afifi RA, Bearinger LH, Blakemore S-J, Dick B, Ezeh AC, Patton GC. Adolescence: a foundation for future health. Lancet. 2012;379:1630-40. https://doi.org/10.1016/S0140-6736(12)60072-5.

22. Viner RM, Ozer EM, Denny S, Marmot M, Resnick M, Fatusi A, Currie C. Adolescence and the social determinants of health. Lancet. 2012;379:1641-52.

23. Catalano RF, Hawkins JD. The social development model. In: Hawkins JD, editor. A theory of antisocial behavior: Deliquency and crime therories; 1996. p. 149-97.

24. Masten AS. Global perspectives on resilience in children and youth. Child Dev. 2014;85:6-20. https://doi.org/10.1111/cdev.12205.

25. Cohen AL. The social development model. EBSCO Research Starters; 2008. p. 1-7.

26. Hawkins JD, Weis JG. The social development model: an integrated approach to delinquency prevention. J Prim Prev. 1985;6:73-97. https://doi. org/10.1007/BF01325432.

27. Schubert H. Evaluation des Modellproprogramms "communities that care" in Niedersachsen: Theoretische Grundlagen und empirische Befunde zur sozialräumlichen Prävention in Netzwerken. Evaluation of the model program "communities that care" in lower Saxony: theoretical basics and empirical findings on sociospatial prevention in networks. Köln: Verl. Sozial, Raum, Management; 2013.

28. Lyssenko L, Rottmann N, Bengel J. Research on psychological resilience. Relevance for prevention and health promotion. Bundesgesundheitsblatt Gesundheitsforschung Gesundheitsschutz. 2010;53:1067-72. https://doi.org/ 10.1007/s00103-010-1127-7.

29. Bengel J, Meinders-Lücking F, Rottmann N. Schutzfaktoren bei Kindern und Jugendlichen: stand der Forschung zu psychosozialen Schutzfaktoren für Gesundheit. Protective factors in children and adolescents: state of research on psychosocial protection factors for health. Köln: Bundeszentrale für Gesundheitliche Aufklärung; 2009.

30. Werner EE. The children of Kauai: resiliency and recovery in adolescence and adulthood. J Adolesc Health. 1992;13:262-8.

31. Masten AS. Regulatory processes, risk, and resilience in adolescent development. Ann New York Acad Sci. 2004;1021:310-9. https://doi.org/10 1196/annals.1308.036.

32. Tapia JA, Rueda C, Fuentes CA. Development and validation of the family motivational Questionnaiere (FMC-Q). Psicothema. 2013;25:266-74. https:// doi.org/10.7334/psicothema2012.218

33. Véronneau M-H, Dishion TJ. Predicting change in early adolescent problem behavior in the middle school years: a Mesosystemic perspective on parenting and peer experiences. J Abnorm Child Psychol. 2010;38:1125-37. https://doi.org/10.1007/s10802-010-9431-0.

34. Piko BF, Luszczynska A, Fitzpatrick KM. Social inequalities in adolescent depression: the role of parental social support and optimism. Int J Soc Psychiat. 2013;59:474-81. https://doi.org/10.1177/0020764012440788. 
35. Costello D, Swendsen J, Rose J, Dierker L. Risk and protective factors associated with trajectories of depressed mood from adolescence to early adulthood. J Consult Clin Psychol. 2008;76:173-83. https://doi.org/10.1037/ 0022-006X.76.2.173.

36. van Voorhees B, Paunesku D, Kuwabara S, Basu A, Gollan J, Hankin B, et al. Protective and vulnerability factors predicting new-onset depressive episode in a representative of U.S. adolescents. J Adolesc Health. 2008;42:605-16. https://doi.org/10.1016/j.jadohealth.2007.11.135.

37. Wolstein J, Wurdak M, Stürmer M. Evaluation des Alkoholpräventionsprojektes HaLT - Hart am Limit in Bayern. München: Evaluation of the alcohol prevention project HaLT - Hart am Limit in Bavaria; 2011.

38. Steiner M., Knittel T. The national pilot project HaLT - scientific monitoring. 2007. http://www.prognos.com/fileadmin/pdf/publikationsdatenbank/ HaLT\%20Short\%20Report.pdf. Accessed 6 Jul 2016.

39. Kuttler $\mathrm{H}$, Schwendemann $\mathrm{H}$, Reis O, Bitzer EM. Developmental hazards among young alcohol intoxicated patients. J Adolesc Health. 2016;59:87-95. https://doi.org/10.1016/j.jadohealth.2016.03.022.

40. Groeger-Roth F, Frisch JU, Benit N, Soellner R. Risikofaktoren für problematischen Substanzkonsum von Jugendlichen - Zur Anwendbarkeit des communities that care Schülersurveys auf kommunaler Ebene. Risk factors for problematic substance use - is the communities that care youth survey applicable in german communities? Sucht. 2015;61:237-49. https:// doi.org/10.1024/0939-5911.a000379.

41. Groeger-Roth F. Lokale Risiko- und Schutzfaktoren für Jugendkriminalität. Die Rolle von sozialräumlichen Unterschieden für die kommunale Prävention. Local risk and protection factors for juvenile crime. The role of socio-spatial differences for community prevention. Social spatial work in the offenders assistance. Sozialräumliches Arbeiten in der Straffälligenhilfe. 2012:73-89.

42. Groeger-Roth F. dt. Version des CTC - Itemkennwerte 11/2013. Frankfurt.

43. Arthur MW, Briney JS, Hawkins JD, Abbott RD, Brooke-Weiss BL, Catalano RF. Measuring risk and protection in communities using the communities that care youth survey. Eval Program Plann. 2007;30:197-211. https://doi.org/10. 1016/j.evalprogplan.2007.01.009.

44. Leys C, Ley C, Klein O, Bernard P, Licata L. Detecting outliers: do not use standard deviation around the mean, use absolute deviation around the median. J Exp Soc Psychol. 2013;49:764-6. https://doi.org/10.1016/j.jesp.2013.03.013.

45. Schwendemann $H$, Kuttler $H$, Bitzer EM. Entwicklungsgefährdung bei Jugendlichen mit Alkoholintoxikation prognostizieren. Predict developmental risk in adolescents with alcohol intoxication. Sucht. 2015;61: 223-36. https://doi.org/10.1024/0939-5911.a000378.

46. Rhew IC, Monahan KC, Oesterle S, Hawkins JD. The communities that care brief depression scale: psychometric properties and criterion validity. J Community Psychol. 2016;44:391-8. https://doi.org/10.1002/jcop.21766.

47. Cole DA, Ciesla JA, Steiger JH. The insidious effects of failing to include designdriven correlated residuals in latent-variable covariance structure analysis. Psychol Methods. 2007;12:381-98. https://doi.org/10.1037/1082-989X.12.4.381.

48. Vandenberg RJ, Lance CE. A review and synthesis of the measurement invariance literature: suggestions, practices, and recommendations for oragnisational research. Organ Res Methods. 2000;3:4-70. https://doi.org/10. 1177/109442810031002.

49. van de Schoot $R$, Schmidt $P$, DeBeuckelaer A. Measurement invariance Lausanne: Frontiers Media SA; 2015.

50. Weiber R, Mühlhaus D. Strukturgleichungsmodellierung: Eine anwendungsorientierte Einführung in die Kausalanalyse mit Hilfe von AMOS, SmartPLS und SPSS. Structural equation modeling: an applicationoriented introduction to causal analysis using AMOS, SmartPLS and SPSS. 2nd ed. Berlin: Springer Gabler; 2014.

51. Little TD. Longitudinal structural equation modeling. Guildford: New York [u. a.]; 2013.

52. Meredith W, Teresi JA. An essay on measurement and factorial invariance. Med Care. 2006;44:S69-77. https://doi.org/10.1097/01.mlr.0000245438.73837.89.

53. Chen FF. Sensitivity of goodness of fit indexes to lack of measurement invariance. Struct Equation Model Multidisciplinary J. 2007;14:464-504. https://doi.org/10.1080/10705510701301834

54. Satorra A, Bentler PM. A scaled difference Chi-Square test statistic for moment structure analysis. Psychometrica. 2001;66:507-14. https://doi.org/ 10.1007/BF02296192.

55. Rosseel Y. Lavaan: an R package for structural equation modeling. J Stat Softw. 2012;48:1-36. https://doi.org/10.18637/jss.v048.i02.

56. Byrne BM. Structural equation modeling with AMOS: basic concepts, applications, and programming. 2nd ed. New York: Routledge; 2010.
57. Oberski D. Lavaan.Survey: an R package for complex survey analysis of structural equation modeling. J Stat Softw. 2014;57:1-27. https://doi.org/10. 18637/jss.v057.i01

58. Stekhoven DJ. Using the missForest package. 2011. http://stat.ethz.ch/education/ semesters/ss2012/ams/paper/missForest_1.2.pdf. Accessed 6 Jul 2016.

59. Frisch JU, Soellner R, Groeger-Roth F. Community based prevention: does communities that care (CTC) methodology apply to Germany? San Fransico; 2.6.2016.

60. Soellner R, Frisch JU, Reder M. Communities That Care: Schülerbefragung in Niedersachsen. Hildesheim: Universitätsverlag Hildesheim; 2016.

61. Huang B, Kosterman R, Catalano RF, Hawkins JD, Abbott RD. Modeling mediation in the etiology of violent behavior in adolescence: a test of the social development model. Criminology. 2001;39:75-108. https://doi.org/10. 1111/j.1745-9125.2001.tb00917.x.

62. Zimmermann $P$, Iwanski A. Bindung und Automnomie im Jugendalter. In: Neider A, Bleckmann P, Brisch KH, editors. Krisenbewältigung, Widerstandskräfte, Soziale Bindungen im Kindes- und Jugendalter // Bindung und Jugend: Individualität, Gruppen und Autonomie. 1st ed. Stuttgart: Verl. Freies Geistesleben; Klett-Cotta; 2014. p. 12-35.

63. Koehn AJ, Kerns KA. Parent-child attachment: meta-analysis of associations with parenting behaviors in middle childhood and adolescence. Attach Hum Dev. 2017:1-28. https://doi.org/10.1080/14616734.2017.1408131.

64. Amann U. Substanzmissbrauch im Jugendalter und Bindungserfahrungen: wissenschaftliche Ergebnisse und Erfahrungen aus der Praxis der JugendSuchtstation clean.kick und clean.kids. In: Neider A, Bleckmann P, Brisch KH, editors. Krisenbewältigung, Widerstandskräfte, Soziale Bindungen im Kindesund Jugendalter // Bindung und Jugend: Individualität, Gruppen und Autonomie. 1st ed. Stuttgart: Verl. Freies Geistesleben; Klett-Cotta; 2014. p. 112-38.

65. Piko BF, Kovacs E, Fitzpatrick KM. What makes a difference? Understanding the role of protective factors in Hungarian adolescents' depressive symptomatology. Eur Child Adolesc Psychiat. 2009;18:617-24. https://doi. org/10.1007/s00787-009-0022-y.

66. Formoso D, Gonzales NA, Aiken LS. Family conflict and children's internalizing and externalizing behavior: protective factors. Am J Community Psychol. 2000; 28:175-99. https://doi.org/10.1023/A:1005135217449.

67. Connor J, Rueter M. Parent-child relationships as systems of support or risk for adolescent suicidality. J Fam Psychol. 2006;20:143-55. https://doi.org/10. 1037/0893-3200.20.1.143.

68. Stappenbeck J, Wendell A, Thomasius R. Evaluation des familienbasierten Programms Familien stärken zur Prävention von Sucht- und Verhaltensproblemen bei Jugendlichen. Evaluation of the family based program "strengthening families" to prevent addictive and behavior problems in adolescents. Gesundheitswesen. 2015;77:S74-5. https://doi.org/ 10.1055/s-0032-1333246

69. Stolle M, Sack P-M, Stappenbeck J, Thomasius R. Familienbasierte Prävention bei Kindern und Jugendlichen. Family-based prevention in children and adolescents. SUCHT - Zeitschrift für Wissenschaft und Praxis / J Addict Res Pract. 2010;56:51-60. https://doi.org/10.1024/0939-5911/a000010.

70. Klocke A. Gesundheit der Kinder in Einelternfamilien. Childrens health in one-parent families. Gesundheitswesen. 2012;74:70-5. https://doi.org/10, 1055/s-0032-1312634.

71. Tomcikova Z, Veselska ZD, Geckova AM, Van Dijk JP, Reijneveld SA. Adolescents' drinking and drunkenness more likely in one-parent families and due to poor communication with mother. Cent Eur J Public Health. 2015;23:54-8. https://doi.org/10.21101/cejph.a3951.

72. Fergusson DM, Beautrais AL, Horwood LJ. Vulnerability and resiliency to suicidal behaviours in young people. Psychol Med. 2003;33:61-73.

73. Lohaus A, Vierhaus M. Entwicklungspsychologie des Kindes- und Jugendalters für bachelor. Developmental Psychology of childhood and adolescence for bachelor. 3rd ed. Berlin: Springer; 2015. 